\title{
Effects of plant growth-promoting rhizobacteria on nodulation of Phaseolus vulgaris $L$. are dependent on plant $P$ nutrition
}

\author{
Roseline Remans · Anja Croonenborghs • \\ Roldan Torres Gutierrez · Jan Michiels • \\ Jos Vanderleyden
}

Received: 8 December 2006/Accepted: 26 April 2007/Published online: 25 May 2007

(c) KNPV 2007

\begin{abstract}
Several plant growth-promoting rhizobacteria (PGPR) have shown potential to enhance nodulation of legumes when coinoculated with $R h i$ zobium. To optimize the efficiency of these Rhizobium-PGPR-host plant interactions, unravelling the underlying mechanisms and analyzing the influence of specific environmental conditions is crucial. In this work the effect of four PGPR strains on the symbiotic interaction between Rhizobium and common bean (Phaseolus vulgaris) was studied under deficient versus sufficient phosphorus supply. It was observed that the effect on nodulation of three out of four PGPR tested was strongly dependent on P nutrition. Further, the use of specific PGPR mutant strains indicated that bacterial indole-3-acetic-acid production (IAA) and 1-aminocyclopropane-1-carboxylate (ACC) deaminase activity play an important role in the host nodulation response, particularly under low $\mathrm{P}$ conditions. Moreover, it was shown that the differential response to PGPR under low versus high $\mathrm{P}$ conditions was associated with changes in the host hormone sensitivity for nodulation induced under $\mathrm{P}$ deficiency. These findings contribute to the understanding of the interplay between Rhizobium, PGPR
\end{abstract}

R. Remans $(\varangle) \cdot$ A. Croonenborghs ·

R. T. Gutierrez · J. Michiels · J. Vanderleyden

Department of Microbial and Molecular Systems, Centre

of Microbial and Plant Genetics, K.U. Leuven,

Kasteelpark Arenberg 20, 3001 Heverlee, Belgium

e-mail: roseline.remans@biw.kuleuven.be and the plant host under different environmental settings.

Keywords Phosphorus deficiency · Nodulation · Common bean · Plant growth-promoting rhizobacteria $\cdot$ Phytohormones

\section{Introduction}

Legumes capable of symbiotic nitrogen fixation are crucial in agricultural crop production (Smith and Hume 1987; Vance 1997; Pepper 2000). Common bean (Phaseolus vulgaris L.) is the most important food legume for direct human consumption in the world (Broughton et al. 2003). In Africa and Latin America, common bean production is often undertaken on small farms using marginal soils low in nitrogen (N) and phosphorus (P) (Graham 1981; Thung 1991) and with minimal technical inputs. Progressive mining of soil nutrients does occur (Franzluebbers et al. 1998), with P second only to $\mathrm{N}$ as the most limiting factor for plant growth (Vance et al. 2000). P deficiency specifically is a nutritional limiting factor for efficient nodulation and nitrogen fixation (Christiansen and Graham 2002). $\mathrm{N}_{2}$ fixation in legumes is a P-requiring process. Nodules of $\mathrm{P}$-sufficient plants have a higher $\mathrm{P}$ concentration than shoots and roots, and may contain up to $1.5 \%$ of the total plant P (Graham and Rosas 1979; Pereira and 
Bliss 1987, Schulze et al. 2006). Al-Niemi et al. (1997) suggest that nodule bacteroids in beans may be $\mathrm{P}$ limited even though the plant is well supplied with P. P-deficient plants exhibit reduced carbohydrate supply to nodules, and are usually restricted in nodule initiation, development and growth, and in nitrogenase activity (Graham and Rosas 1979; Pereira and Bliss 1987; Vadez et al. 1999; Kouas et al. 2005; Schulze et al. 2006).

Simultaneous inoculation with Rhizobium and other plant growth-promoting bacteria has shown potential to enhance plant growth, nodulation and nitrogen fixation of several legumes. Examples are numerous. Dual inoculation with Azotobacter spp. or Azospirillum spp. and Rhizobium strains showed a synergistic effect on nodulation, plant growth, yield and $\mathrm{N}$ uptake in soybean, clover, common bean and peanut (Burns et al. 1981; Raverker and Konde 1988; Burdman et al. 1997). Similarly, coinoculation with Pseudomonas spp. and Rhizobium spp. has been reported to enhance nodulation and nitrogen fixation, plant biomass and grain yield in various leguminous species including alfalfa (Bolton et al. 1990), soybean (Dashti et al. 1998), green gram (Sindhu et al. 1999) and chickpea (Goel et al. 2002). Coinoculation with Bacillus spp. and Rhizobium or Bradyrhizobium spp. ameliorated the nodulation and plant growth of common bean and soybean respectively (Srinivasan et al. 1997; Camacho et al. 2001; Bai et al. 2003). The mechanisms used by rhizobacteria to promote nodulation and nitrogen fixation are mostly unknown or remain ambiguous. Increased root development and nutrient uptake induced by plant growth-promoting rhizobacteria (PGPR) and their metabolites (reviewed by Lugtenberg et al. 2002; PerselloCartieaux et al. 2003) may indirectly contribute to nodulation and nitrogen fixation (Vessey and Buss 2002). Evidence for a more direct effect on nodulation was described by Volpin et al. (1996) and Burdman et al. (1996). They observed that A. brasilense increased the exudation of flavonoids, plant signalling molecules crucial in the establishment of the Rhizobium-legume symbiosis, in the alfalfa and common bean rhizosphere. The use of a gusA-marked Azospirillum strain in an AzospirillumRhizobium coinoculation experiment on white clover demonstrated that Azospirillum colonized the tap root, root hairs and sites near or on the nodules (Tchebotar et al. 1998). Taken together with the observation that non-nodulated plants form more root hairs and lateral roots (Plazinski and Rolfe 1985a), it is suggested that when coinoculated with Rhizobium, Azospirillum stimulates the formation of epidermal cells that become infected root hair cells, or creates additional infection sites that are later occupied by rhizobia (Plazinski and Rolfe 1985c; Tchebotar et al. 1998). Recently, Thilak et al. (2006) showed that PGPR in conjunction with efficient Rhizobium can also affect the growth and nitrogen fixation in pigeon pea by enhancing the occupancy of introduced Rhizobium in the nodules of the legume. The nodule occupancy of the introduced Rhizobium strain increased from 50\% (with Rhizobium alone) to $85 \%$ in the presence of Pseudomonas putida.

Positive effects of PGPR on nodulation, nitrogen fixation and plant growth of legumes have been observed in greenhouse experiments using hydroponic, vermiculite-based and soil-based systems as well as in field experiments (Burdman et al. 1997; Bai et al. 2003; Hamaoui et al. 2001). However, the influence of specific environmental factors on these Rhizobium-PGPR-plant interplays has not yet been studied. In the present work, the effect of different PGPR on the Rhizobium-bean symbiosis was evaluated under deficient versus sufficient $\mathrm{P}$ supply, thereby exploring the potential of Rhizobium-PGPR coinoculation to enhance nitrogen fixation under $\mathrm{P}$ deficiency. To initiate mechanistic studies of the synergistic effects, wild-type and specific mutants of some of the PGPR tested were used for the first time in Rhizobium-PGPR coinoculation experiments.

\section{Materials and methods}

Bacterial strains and growth conditions

The strains used in this study are listed in Table 1. Rhizobium etli CNPAF512 was grown overnight in liquid tryptone-yeast extract (TY) medium at $30^{\circ} \mathrm{C}$ or maintained on yeast extract -mannitol (YEM) (Vincent 1970) agar plates (15 g agar $\mathrm{l}^{-1}$ ). Azospirillum brasilense $\mathrm{Sp} 245$ was grown overnight in liquid $\mathrm{L}^{*}$ broth, which is Luria-Bertani broth medium (Sambrook et al. 1989) supplemented with $2.5 \mathrm{mM}$ $\mathrm{CaCl}_{2}$ and $2.5 \mathrm{mM} \mathrm{MgSO}_{4}$, at $30^{\circ} \mathrm{C}$ or maintained on yeast extract-peptone agar plates (YEP) 
Table 1 Bacterial strains used in this study

\begin{tabular}{|c|c|c|}
\hline Bacterial strains & Relevant characteristics & Reference \\
\hline $\begin{array}{l}\text { Rhizobium etli } \\
\text { CNPAF512 }\end{array}$ & Wild-type strain, isolated from Phaseolus vulgaris nodules, Brazil & $\begin{array}{l}\text { Michiels et al. } \\
\text { (1998) }\end{array}$ \\
\hline $\begin{array}{l}\text { Azospirillum brasilense } \\
\text { Sp245 }\end{array}$ & Wild-type strain, isolated from surface-sterilized wheat roots, Brazil & $\begin{array}{l}\text { Baldani et al. } \\
\text { (1986) }\end{array}$ \\
\hline FAJ009 & ipdC Tn5 mutant of $A$. brasilense $\mathrm{Sp} 245 ; \mathrm{Km}^{\mathrm{r}}$ & $\begin{array}{l}\text { Costacurta et al. } \\
\quad(1994)\end{array}$ \\
\hline $\begin{array}{l}\text { Bacillus subtilis } \\
\quad \text { LMG7135 }\end{array}$ & Wild-type strain, LMG bacteria collection & $\begin{array}{l}\text { Chun and Bae } \\
\text { (2000) }\end{array}$ \\
\hline $\begin{array}{l}\text { Pseudomonas putida } \\
\text { UW4 }\end{array}$ & $\begin{array}{l}\text { Wild-type strain, isolated from the rhizosphere of reeds and selected for ACC } \\
\text { deaminase activity, Canada }\end{array}$ & Glick et al. (1995) \\
\hline $\mathrm{UW}^{4} / \mathrm{AcdS}^{-}$ & AcdS, ACC deaminase mutant of $P$. putida, $\mathrm{Tc}^{\mathrm{r}}$ & Li et al. (2000) \\
\hline $\begin{array}{l}\text { Pseudomonas fluorescens } \\
\text { SBW25 }\end{array}$ & Wild-type SBW25 & $\begin{array}{l}\text { Rainey and Baily } \\
\text { (1996) }\end{array}$ \\
\hline
\end{tabular}

(15 $\mathrm{g}$ agar $\mathrm{1}^{-1}$ ). Bacillus subtilis LMG7135 was grown overnight in liquid TY medium at $30^{\circ} \mathrm{C}$ or maintained on TY agar plates $\left(15 \mathrm{~g}\right.$ agar $\left.1^{-1}\right)$. Pseudomonas strains, Pseudomonas fluorescens SBW25 and Pseudomonas putida UW4, were grown in liquid Tryptic Soy Broth (TSB) medium at $30^{\circ} \mathrm{C}$ or maintained on TSB agar plates $\left(15 \mathrm{~g}\right.$ agar $\left.1^{-1}\right)$. For the genetically modified strains the antibiotics kanamycin $(\mathrm{Km})$ or tetracycline $(\mathrm{Tc})$ were added to a final concentration of 25 and $10 \mu \mathrm{g} \mathrm{ml}^{-1}$ respectively.

Preparation of bacterial inocula

Pure cultures were grown overnight at $30^{\circ} \mathrm{C}$ in liquid medium (see above). Cells were washed twice with $10 \mathrm{mM} \mathrm{MgSO}_{4}$ and resuspended in $10 \mathrm{mM} \mathrm{MgSO}_{4}$ at a density of $10^{7}$ colony forming units (cfu) $\mathrm{ml}^{-1}$ for Rhizobium or at a density of $10^{9} \mathrm{cfu} \mathrm{m}^{-1}$ for Azospirillum, Bacillus and Pseudomonas strains. Rhizobium inoculum contained only Rhizobium cells at a density of $10^{7} \mathrm{cfu} \mathrm{ml}{ }^{-1} \mathrm{MgSO}_{4}$. Coinoculants contained Rhizobium cells at a density of $10^{7} \mathrm{cfu} \mathrm{ml}^{-1}$ and cells of other specified bacteria at a density of $10^{9} \mathrm{cfu} \mathrm{ml}^{-1} \mathrm{MgSO}_{4}$.

Plant material and growth conditions

Seeds of Phaseolus vulgaris cvs BAT477 were kindly provided by the International Centre of Tropical Agriculture (CIAT), Cali, Colombia. A hydroponic system with a perlite-matrix was optimized to grow bean plants under low versus high $\mathrm{P}$ conditions in the greenhouse. One litre pots filled with perlite were initially moistened with $250 \mathrm{ml}$ nitrogen-free medium (based on Snoeck et al. 2003). During growth a drip irrigation system maintained the $\mathrm{pH}(\mathrm{pH}$ 6) and concentration of nutrients in the pots. The high $\mathrm{P}$ culture medium contained $100 \mu \mathrm{M} \quad \mathrm{KH}_{2} \mathrm{PO}_{4}$, $1.71 \mathrm{mM} \mathrm{K}_{2} \mathrm{SO}_{4}, 0.48 \mathrm{mM} \mathrm{MgSO}{ }_{4}, 0.70 \mathrm{mM} \mathrm{MgCl}$ and $1.06 \mathrm{mM} \mathrm{CaCl}_{2}$. The low $\mathrm{P}$ medium was identical to the high $\mathrm{P}$ medium apart from the concentration of $\mathrm{KH}_{2} \mathrm{PO}_{4}$, which was $1 \mu \mathrm{M}$ in low $\mathrm{P}$ conditions, and the concentration of $\mathrm{K}_{2} \mathrm{SO}_{4}$, which was $1.76 \mathrm{mM}$ in low $\mathrm{P}$ medium (to maintain equal amounts of potassium under low versus high $\mathrm{P}$ conditions). An initial gift of $0.5 \mathrm{mmol} \mathrm{KNO}_{3}$ was added to each pot at sowing.

The seeds of bean cv. BAT477 were surfacesterilized as described previously (Vlassak et al. 1998) and pre-germinated during two days on moist filter paper in the dark at $28^{\circ} \mathrm{C}$. One pre-germinated seedling was planted per pot. The seedlings were inoculated with $200 \mu \mathrm{l}$ inoculum (prepared as described above) containing $10^{6}$ Rhizobium cells or $10^{6}$ Rhizobium cells and $10^{8}$ cells of Azospirillum, Bacillus or Pseudomonas. The number of cells used for inoculation is based on previous research described by Burdman et al. (1996), Burdman et al. (1997), Hamaoui et al. (2001) and Bai et al. (2002). For each condition 12 plants were used and arranged in a randomised block design. Plants were harvested at 21 and/or 42 days after inoculation (DAI) for determination of nodule number, nodule dry weight, shoot dry weight, root dry weight and NPK contents. 
Hormone treatments

Low and high $\mathrm{P}$ culture media were supplemented with $0,10,100$ or $200 \mathrm{nM}$ indole-3-acetic acid (IAA). IAA was solubilised in ethanol at a concentration of $0.1 \mathrm{M}$ before adding to the nutrient solution. IAA was purchased from Sigma Chemicals.

Plant analysis for NPK contents

Total $\mathrm{N}$ content $(\% \mathrm{~N})$ was measured by ignition with a Variomax $\mathrm{CN}$ analyser. Total $\mathrm{P}$ and $\mathrm{K}$ contents $(\% \mathrm{P}, \% \mathrm{~K})$ of shoot, root and nodule tissues were measured by Inductively Coupled Plasma-Optical Emission Spectroscopy (ICP-OES, Perkin Elmer, Optima 3300 DV, axial plasma).

\section{Statistical analysis}

Significance of difference between inoculation treatments and $\mathrm{P}$ levels was determined by the TukeyKramer Honestly Significant Difference Test at $P=0.05$, using the SAS programme (SAS 9.1) (SAS Institute 1996). All experiments were performed at least twice, yielding similar results.

\section{Results}

Nodulation and plant growth parameters under deficient versus sufficient $\mathrm{P}$ conditions

BAT477 bean plants were inoculated with Rhizobium etli CNPAF512 and grown under low and high $\mathrm{P}$ conditions in the greenhouse. Plant growth and nodulation parameters were determined at harvest 42 DAI. The results, summarized in Table 2, show that (i) plants grown under low $\mathrm{P}(1 \mu \mathrm{M})$ conditions used in our experimental set-up are deficient in P; (ii) nodulation is more reduced than plant growth under $\mathrm{P}$ deficiency and (iii) nodules contain a higher concentration of $\mathrm{P}$ than other plant parts under high as well as under low $\mathrm{P}$ conditions. These results are consistent with previous observed effects of $\mathrm{P}$ deficiency on nodulation and growth parameters of common bean and other legumes.
Effect of PGPR on nodulation and plant growth parameters of bean under low versus high $\mathrm{P}$ conditions

BAT477 bean plants were inoculated with Rhizobium etli CNPAF512 or coinoculated with Rhizobium and other rhizobacteria, Azospirillum brasilense Sp245, Bacillus subtilis LMG7135, Pseudomonas putida UW4 or Pseudomonas fluorescens SBW25. For each of these rhizobacteria when used as a single inoculum plant growth-promoting activities have been extensively documented in the literature with various plant species. Similarly as described above, plants were grown under low and high $\mathrm{P}$ conditions in the greenhouse and harvested at 42 DAI. The effect of coinoculation on nodule number under high and low $\mathrm{P}$ conditions is shown in Fig. 1a, b respectively. In this figure the nodule number for each inoculation treatment is presented as \% nodule number of plants inoculated with Rhizobium only. Under high $\mathrm{P}$ conditions, coinoculation with Rhizobium and A. brasilense Sp245 or with Rhizobium and B. subtilis LMG7135 significantly $(P<0.05)$ increased bean nodulation. However, under $\mathrm{P}$ deficient conditions, this positive effect of Sp245 and LMG7135 was not observed. On the contrary coinoculation with A. brasilense $\mathrm{Sp} 245$ resulted in a strong reduction of nodulation under low P. LMG7135 did not affect nodulation significantly under low $\mathrm{P}$. The reverse effect of $\mathrm{P}$ nutrition was observed for coinoculation with Rhizobium and P. putida UW4. UW4 enhanced nodulation strongly under $\mathrm{P}$ deficiency but only slightly under P-sufficient conditions. Pseudomonas fluorescens SBW25 did not affect nodule number of bean line BAT477 significantly under the conditions tested.

Similar effects of the PGPR strains used were observed on nodule dry weight (data not shown), shoot dry weight (Fig. 1c, d) and root dry weight (Fig. 1e, f) under low versus high $P$ conditions. The similarity in response to PGPR of nodule number, shoot and root dry weight strongly suggests a correlation between nodulation and plant growth parameters. Coinoculation with Rhizobium and PGPR did not affect plant NPK concentrations, only total NPK contents (data not shown). 
Table 2 Nodulation and growth parameters of BAT477 bean plants inoculated with Rhizobium etli CNPAF512 and grown under low $\mathrm{P}\left(1 \mu \mathrm{M} \mathrm{KH} \mathrm{KO}_{4}\right)$ and high $\mathrm{P}\left(100 \mu \mathrm{M} \mathrm{KH} \mathrm{KHO}_{4}\right)$ conditions

\begin{tabular}{|c|c|c|c|}
\hline & High P & Low $\mathrm{P}$ & Low $\mathrm{P}$ As $\%$ of high $\mathrm{P}$ \\
\hline Nodule number & $359.2 \pm 39$ & $107.5 \pm 18$ & $29.8 *$ \\
\hline Nodule dry weight (mg) & $200.4 \pm 30.8$ & $25.9 \pm 5.6$ & $12.9^{*}$ \\
\hline Acetylene reduction Activity ( $\mu$ l ethylene $\mathrm{h}^{-1}$ ) & $7.1 \pm 1.45$ & $0 \pm 0$ & $0 *$ \\
\hline Shoot dry weight (SDW) (g) & $2.06 \pm 0.34$ & $0.74 \pm 0.18$ & $35.9 *$ \\
\hline Root dry weight (RDW) (g) & $0.51 \pm 0.08$ & $0.37 \pm 0.05$ & $72.6^{*}$ \\
\hline $\mathrm{SDW} / \mathrm{RDW}$ & $4.04 \pm 0.12$ & $2.00 \pm 0.09$ & $49.5^{*}$ \\
\hline Shoot $\% \mathrm{~N}$ & $3.86 \pm 0.36$ & $3.31 \pm 0.25$ & 85.8 \\
\hline Shoot \% C & $43.9 \pm 0.44$ & $42.4 \pm 0.76$ & 96.4 \\
\hline Shoot \% P & $0.22 \pm 0.02$ & $0.08 \pm 0.02$ & $36.4^{*}$ \\
\hline Shoot N/P & $17.53 \pm 1.06$ & $41.40 \pm 4.45$ & $236.2^{*}$ \\
\hline Root \% P & $0.25 \pm 0.03$ & $0.16 \pm 0.02$ & $64.0 *$ \\
\hline Nodules \% P & $0.46 \pm 0.05$ & $0.34 \pm 0.04$ & $73.2^{*}$ \\
\hline Total N (mg) & $146.5 \pm 24.91$ & $24.5 \pm 6.56$ & $16.7 *$ \\
\hline Total C (mg) & $905.82 \pm 121.7$ & $313.64 \pm 45.6$ & $34.6 *$ \\
\hline Total P (mg) & $4.53 \pm 0.83$ & $0.59 \pm 0.12$ & $13.0 *$ \\
\hline
\end{tabular}

Values are averages of 12 plants \pm standard deviations

$* P<0.05$ Tukey-Kramer for difference between low $\mathrm{P}$ and high $\mathrm{P}$ values

Differential nodulation and growth response to PGPR under low versus high $\mathrm{P}$ is associated with production or conversion of phytohormones by PGPR

To delineate the mechanisms by which PGPR contribute to the differential nodulation response under low versus high $\mathrm{P}$ conditions, PGPR mutant strains affected in genes known to be involved in their plant growth-promoting effect were used. Bean plants were inoculated with Rhizobium, coinoculated with Rhizobium and a wild-type PGPR strain or with Rhizobium and a mutant PGPR strain, and grown during 42 days under low and high $\mathrm{P}$ conditions in the greenhouse. This allowed us to compare the effect of the mutant and wild-type PGPR strain on nodulation and to evaluate the role of the mutations in the modulation of nodulation.

Figure 2a, b shows that the effect of coinoculation on nodulation was less pronounced when the mutant strain FAJ009 of A. brasilense and the $\mathrm{UW} /$ AcdS $^{-}$mutant of $P$. putida UW4 were used instead of parent wild-type strains. FAJ009 is an insertion mutant of A. brasilense Sp245 in which the indole-3-pyruvate decarboxylase (ipdC) gene is inactivated, resulting in $90 \%$ reduction of production of the phytohormone indole-3-acetic acid in FAJ009 as compared to the wild-type Sp245 strain (Costacurta et al. 1994; Vande Broek et al. 1999). $\mathrm{UW} / \mathrm{AcdS}^{-}$(Li et al. 2000) is an insertion mutant of $P$. putida UW4 in which the gene encoding the enzyme 1-aminocyclopropane-1-carboxylate deaminase (ACCD) is inactivated. The enzyme 1-aminocyclopropane-1-carboxylate deaminase converts ACC, the precursor of the plant hormone ethylene, to alpha-ketobutyrate and ammonium and thereby reduces the production of ethylene. The mutations in FAJ009 and UW4/AcdS ${ }^{-}$have been described to be stable without antibiotic selection by Dobbelaere et al. (1999) for FAJ009 and by Hontzeas et al. (2004) for $\mathrm{UW} / \mathrm{AcdS}^{-}$. In the media used no differences in growth rate were observed between wild-type and mutant strains.

Under low P conditions, FAJ009 did not affect nodulation significantly while the Sp245 wild-type strain reduced nodule number by $36 \%$ as compared to single Rhizobium inoculation. Under high P conditions, FAJ009 enhanced nodule number significantly, but the increase in nodulation was less pronounced compared to coinoculation with the wild-type strain. 

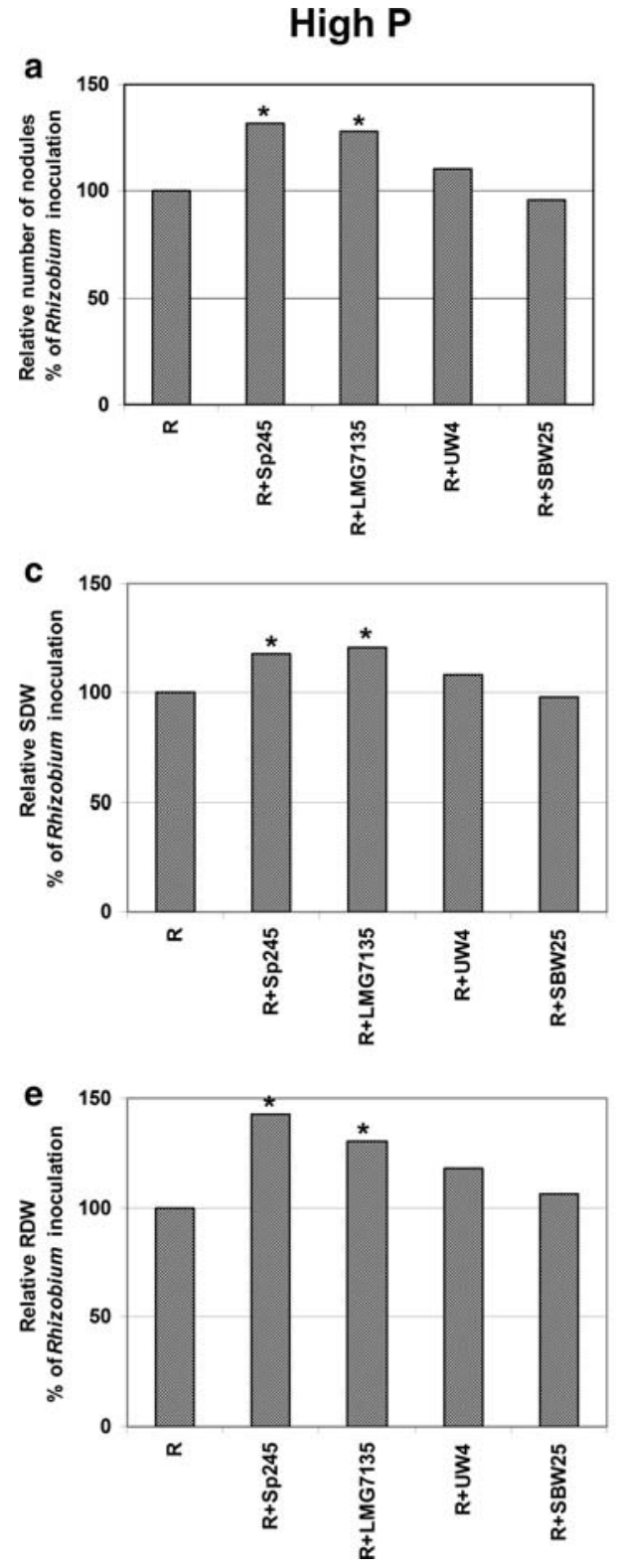

Fig. 1 Effect of PGPR on nodulation and plant parameters under high and low $\mathrm{P}$ conditions. Bars represent percentages of (a) nodule number per plant under high P; (b) nodule per plant number under low P; (c) plant shoot dry weight (SDW) under high P; (d) SDW under low P; (e) plant root dry weight (RDW) under high P (f) RDW under low P of BAT477 plants inoculated with Rhizobium etli CNPAF512 (R) or coinoculated with Rhizobium and A. brasilense $\mathrm{Sp} 245(\mathrm{R}+\mathrm{Sp} 245)$, B. subtilis

Inactivation of the ACC-deaminase in P. putida UW4 reduced the positive effect on nodulation of UW4 under low $\mathrm{P}$ conditions. Under high $\mathrm{P}$ conditions, no
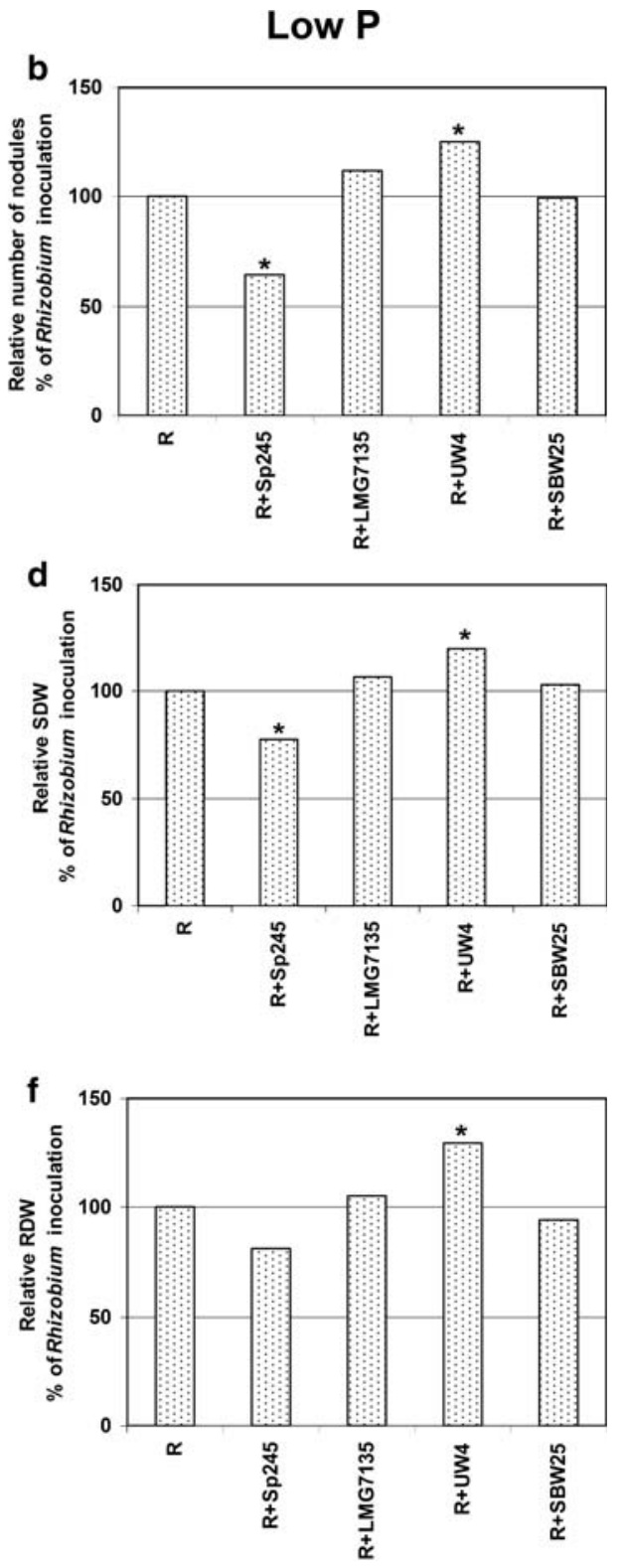

LMG7135 (R + LMG7135), P. putida UW4 (R + UW4), P. fluorescens SBW25 (R + SBW25). 100\% represents the average value of plants inoculated with Rhizobium alone (see Table 1 for absolute values of nodule number, SDW, RDW). Plants were grown for 42 days under low and high $\mathrm{P}$ conditions and harvested for nodulation and plant parameters analysis. 12 plants per condition were used. $* P<0.05$ Tukey-Kramer. This experiment was performed three times, yielding similar results

significant differences were observed between single Rhizobium inoculation and coinoculation with Rhizobium and UW4 or its ACCD minus mutant. 


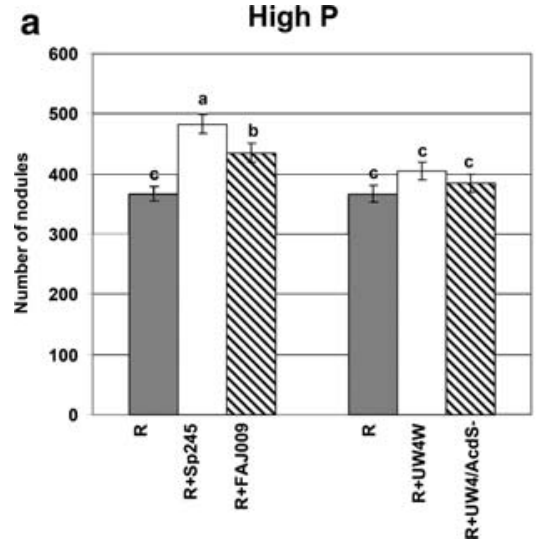

Fig. 2 The effect on nodule number of mutant strains of PGPR compared to the effect of their wild-type strain under (a) high $P$ and (b) low P conditions. Bars represent average values of nodule number of BAT477 bean plants inoculated with Rhizobium etli CNPAF512 (R), coinoculated with Rhizobium and the wild-type strain of A. brasilense Sp245 $(\mathrm{R}+\mathrm{Sp} 245$ WT, white bars) or the wild-type strain of $P$. putida UW4 (R + UW4 WT, white bars), or coinoculated with Rhizobium and the FAJ009 mutant of Sp245 (R + FAJ009, striped bars) or

Effect of IAA on nodulation under low versus high $\mathrm{P}$ conditions

To further unravel the role of exogenous IAA in modulation of nodulation under low and high $\mathrm{P}$ conditions, increasing concentrations of IAA were added to the nutrient solution medium of bean plants inoculated with Rhizobium. BAT477 plants were grown for 21 days under low and high $\mathrm{P}$ conditions and harvested for analysis of early nodulation and plant growth. Figure 3 shows the dose-response curve of nodule number per plant (represented as $\%$ of average nodule number at $0 \mathrm{nM}$ IAA) to increasing concentrations of IAA in the nutrient solution. It was observed that IAA at low concentrations enhanced nodule number, while higher concentrations inhibited nodulation under high as well as under low $\mathrm{P}$ conditions. These results underline the dose-dependent effect of IAA on nodulation. This is consistent with what has been described previously for other legumes (Van Noorden et al. 2006; Plazinski and Rolfe 1985b, c). Interestingly, nodulation was more responsive to IAA under $\mathrm{P}$ deficiency than under $\mathrm{P}$ sufficient conditions. Under low $\mathrm{P}$ conditions, a concentration of $100 \mathrm{nM}$ IAA already strongly inhibited nodulation, while the same concentration

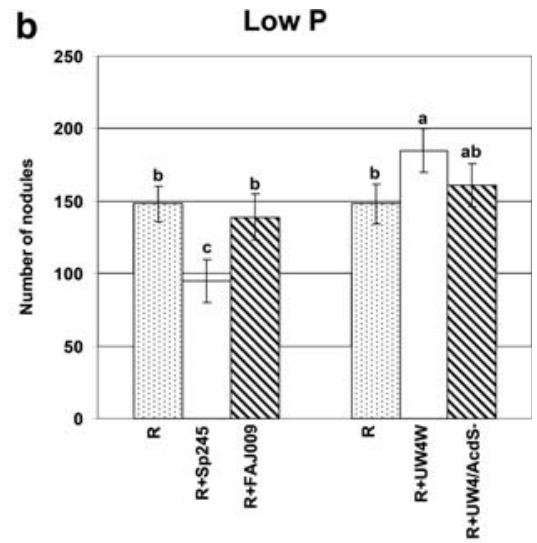

the AcdS ${ }^{-}$mutant of UW4 (R + UW4/AcdS ${ }^{-}$, stride bars). Plants were grown for 42 days under low and high $\mathrm{P}$ conditions and harvested for nodulation and plant parameters analysis. 12 plants per condition were used. Error bars represent $\pm 95 \%$ confidence intervals (Tukey-Kramer). Letters on top of the bars indicate different classes of statistical differences (TukeyKramer). This experiment was performed three times, yielding similar results

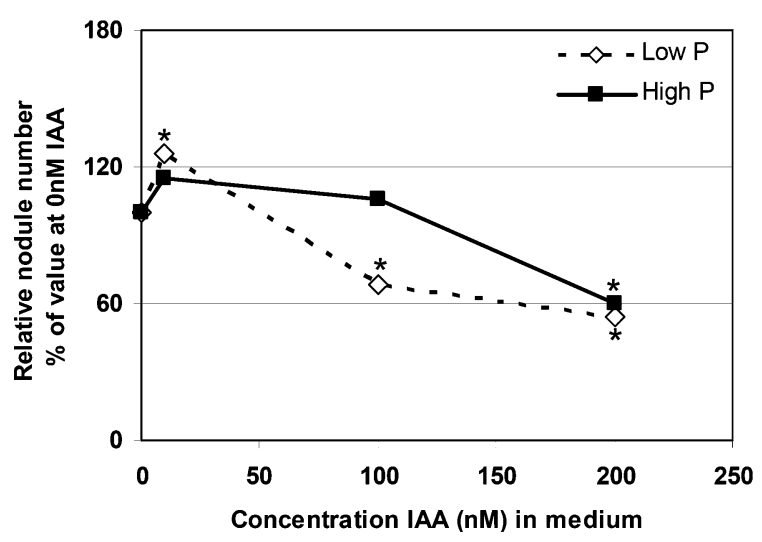

Fig. 3 The effect on nodule number of increasing concentrations of indole-3-acetic acid (IAA) under high $\mathrm{P}$ versus low $\mathrm{P}$ conditions. Points represent percentages of nodule number of BAT477 bean plants inoculated with Rhizobium etli CNPAF512 and grown in the presence of different concentrations of indole-3-acetic acid (IAA) under low P (dashed line) and high $\mathrm{P}$ (full line) conditions. 100\% represents the average nodule number per plant grown at $0 \mathrm{nM}$ IAA. Under high $\mathrm{P}$ $100 \%$ is equal to 142 nodules per plant; under low P $100 \%$ is equal to 85 nodules per plant. Plants were harvested 21 days after inoculation. IAA was added to the nutrient solution as described in materials and methods. * indicates significant difference $(P<0.05$ Tukey-Kramer $)$ for absolute values between plants grown in the presence of IAA and control plants grown in the absence of IAA $(0 \mathrm{nM})$. This experiment was performed three times, yielding similar results 
of IAA under high $\mathrm{P}$ conditions still slightly enhanced nodule number.

\section{Discussion}

This study shows that the effect of PGPR on nodulation and plant growth of bean is dependent on plant $\mathrm{P}$ nutrition. The increase in nodulation induced by $A$. brasilense Sp245 and B. subtilis LMG 7135 observed under high $\mathrm{P}$, was not observed under low $\mathrm{P}$. On the contrary, the positive effect of $P$. putida UW4 was more strongly expressed under $\mathrm{P}$ deficiency than under sufficient $\mathrm{P}$ supply. These results encourage integration of environmental factors including $\mathrm{P}$ nutrition in studies exploring the potential of Rhizobium-PGPR coinoculation to enhance nodulation and plant growth.

The difference in plant and nodulation response under low versus high $\mathrm{P}$ conditions was most pronounced when plants were inoculated with the combination of Rhizobium and A. brasilense Sp245. Under high $\mathrm{P}$ conditions this combination enhanced nodule number, shoot dry weight and root dry weight significantly, while under low $\mathrm{P}$ the same inoculation treatment had a negative effect on these parameters. Intriguingly, using an ipdC mutant of $A$. brasilense Sp245 reduced IAA biosynthesis by $90 \%$ (Costacurta et al. 1994; Vande Broek et al. 1999); it was demonstrated that the Azospirillum IAA production plays a crucial role in the modulation of nodulation, particularly under low $\mathrm{P}$ conditions. This was further supported by experiments in which increasing concentrations of IAA were added to the growth media. The results of these experiments confirm the dosedependent response of nodulation to IAA as described previously (Van Noorden et al. 2006; Plazinski and Rolfe 1985a, b). Low concentrations (up to $100 \mathrm{nM}$ IAA) can enhance nodule number, while higher concentrations inhibit nodulation. Interestingly, Plazinski and Rolfe (1985a, b) described a similar dose-response curve of nodulation in response to inoculation with an increasing number of Azospirillum cells on bean plants.

The experiments using increasing IAA concentrations further showed that nodulation was more sensitive to IAA under low $\mathrm{P}$ than under high $\mathrm{P}$ conditions. Increase in auxin sensitivity under P-deficient conditions has previously been described in Arabidopsis (Lopez-Bucio et al. 2002). The use of Arabidopsis auxin-resistant mutants also demonstrated the crucial role of auxin in root morphological adaptations under low P conditions (Lopez-Bucio et al. 2002; Al-Ghazi et al. 2003). Preliminary data (not shown) of free and conjugated IAA concentrations in BAT477 roots under low and high $\mathrm{P}$ conditions, show that the amount of IAA present in conjugated form is strongly reduced under $\mathrm{P}$ deficiency (Remans et al. unpublished). IAA conjugates play a role in the maintenance of free IAA levels in response to changes in IAA levels (reviewed by Woodward and Bartel 2005), e.g. when exogenous IAA is added, the difference in root IAA conjugate concentrations between low and high $\mathrm{P}$ conditions further supports the observation of increased IAA sensitivity under low P deficiency. Since IAA sensitivity and adaptation to $\mathrm{P}$ deficiency is strongly dependent on the plant genotype, the response to $A$. brasilense Sp245 may also differ strongly across contrasting bean genotypes.

Apart from changes in host sensitivity to IAA, changes in IAA production rate induced in A. brasilense Sp245 under low $\mathrm{P}$ conditions, may also contribute to the differential response in nodulation to Sp245 inoculation under low versus high $\mathrm{P}$ conditions. It has been described that IAA biosynthesis in A. brasilense increases under certain environmental stress conditions, including low pH and carbon stress (Ona et al. 2005). The specific effect of $\mathrm{P}$ deficiency on IAA production in Sp245 has not yet been studied. The negative effect of IAA on plant growth and nodulation is often mediated by ethylene (Persello-Cartieaux et al. 2003). Auxin produced by bacteria in the rhizosphere can stimulate the activity of the 1-aminocyclopropane-1-carboxylate (ACC) synthase, an enzyme used by plants for the synthesis of ethylene (Xie et al. 1996). Ethylene has been shown to negatively regulate the plant's response to the rhizobial bacterial signal, Nod factor (Oldroyd et al. 2001; Penmetsa and Cook 1997). The inhibition of Nod factor-induced calcium spiking reflects the suppression of the Nod factor signalling pathway at a very early stage and most probably explains the regulation of nodule number by ethylene. Borch et al. (1999) reported that $\mathrm{P}$-deficient roots of common bean produced twice as much ethylene $\mathrm{g}^{-1}$ root dry weight than P-sufficient roots. The increased ethylene production in P-deficient roots may contribute to the reduction in nodulation under low $\mathrm{P}$ conditions. Interestingly, the positive effect of coinoculation with Pseudomonas putida UW4 on nodulation was most expressed under low $\mathrm{P}$ conditions. 
This enhancement in nodulation was much less pronounced when an UW4 mutant disabled in ACC deaminase activity was used. These results indicate that bacterial ACC deaminase activity, which reduces ethylene production, may play a crucial role in increasing nodulation and plant growth under $\mathrm{P}$ deficiency. Direct evidence for a positive effect of ACC deaminase activity on nodulation of alfalfa has been described previously by Ma et al. (2004). They showed that the expression of an exogenous ACC deaminase gene in Sinorhizobium meliloti increases its ability to nodulate alfalfa.

In conclusion, this study has showed that $\mathrm{P}$ deficiency alters the effect of PGPR on nodulation and growth of common bean. The differential nodulation response to PGPR under low versus high $\mathrm{P}$ conditions is associated with changes in phytohormone balances induced by specific PGPR. Potential to enhance nodulation and plant growth under $\mathrm{P}$ deficiency by coinoculation with Rhizobium and PGPR does exist, particularly for bacteria possessing ACC deaminase activity. Further research to finetune combinations of Rhizobium, PGPR and host genotype will ultimately lead to better nodulation and stimulated plant growth under low $\mathrm{P}$ conditions.

Acknowledgements R.R. is a recipient of a predoctoral fellowship from the 'Vlaamse Interuniversitaire Raad (VLIR)' R.T. acknowledges the receipt of a predoctoral fellowship from the Katholieke Universiteit Leuven. We thank Dr. Bernard Glick for kindly providing us the strain $P$. putida UW4 and strain $\mathrm{UW}^{4} / \mathrm{AcdS}^{-}$.

\section{References}

Al-Ghazi, Y., Muller, B., Pinloche, S., Tranbarger, T. J., Rossignol, M., Tardieu, F., \& Doumas, P. (2003). Temporal responses of Arabidopsis root architecture to phosphate starvation: Evidence for the involvement of auxin signaling. Plant, Cell and Environment, 26, 1053-1066.

Al-Niemi, T. S., Kahn, M. L., \& McDermott, T. R. (1997). P metabolism in the bean-Rhizobium-tropici symbiosis. Plant Physiology, 113, 1233-1242.

Bai, Y., Panb, B., Charlesc, T., \& Smith, D. (2002). Co-inoculation dose and root zone temperature for plant growth promoting rhizobacteria on soybean [Glycine max (L.) Merr] grown in soil-less media. Soil Biology and Biochemistry, 34, 1953-1957.

Bai, Y., Zhou, X., \& Smith, D. (2003). Enhanced soybean plant growth resulting from coinoculation of Bacillus strains with Bradyrhizobium japonicum. Crop Science, 43, 1174-1781.
Baldani, V. L. D., Alvarez, M. A. B., Baldani, J. I., \& Döbereiner, J. (1986). Establishment of inoculated Azospirillum spp. in the rhizosphere and in roots of field grown wheat and sorghum. Plant Soil, 90, 37-40.

Bolton, H., Elliott, L. F., Turco, R. F., \& Kennedy, A. C. (1990). Rhizoplane colonization of pea seedlings by Rhizobium leguminosarum and a deleterious root colonizing Pseudomonas sp. and effects on plant growth. Plant Soil, 123, 121-124.

Borch, K., Bouma, T. J., Lynch, J. P., \& Brown, K. M. (1999). Ethylene: A regulator of root architectural responses to soil phosphorus availability. Plant Cell Environment, 22, 425-431.

Broughton, W. J., Hernander, G., Blair, B., Beebe, S., Gepts, P., \& Vanderleyden, J. (2003). Beans (Phaseolus spp.) model food legumes. Plant Soil, 252, 55-128.

Burdman, S., Kigel, J., \& Okon, Y. (1997). Effects of Azospirillum brasilense on nodulation and growth of common bean (Phaseolus vulgaris L.). Soil Biology and Biochemistry, 29, 923-929.

Burdman, S., Volpin, H., Kigel, J., Kapulnik, Y., \& Okon, Y. (1996). Promotion of nod gene inducers and nodulation in common bean (Phaseolus vulgaris) roots inoculated with Azospirillum brasilense Cd. Applied and Environmental Microbiology, 62, 3030-3033.

Burns, T. A., Bishop, P. E., \& Israel, D. W. (1981). Enhanced nodulation of leguminous plant roots by mixed cultures of Azotobacter vinelandi and damping-off of tomato by Pseudomonas aeruginosa 7NSK2. Applied and Environmental Microbiology, 62, 865-871.

Camacho, M., Santamaria, C., Temprano, F., RodriguezNavarro, D. N., \& Daza, A. (2001). Co-inoculation with Bacillus sp. CECT 450 improves nodulation in Phaseolus vulgaris L. Canadian Journal of Microbiology, 47, 10581062.

Christiansen, I., \& Graham, P. H. (2002). Variation in dinitrogen fixation among Andean bean (Phaseolus vulgaris L.) genotypes grown at low and high levels of phosphorus supply. Fields Crops Research, 73, 133-142.

Chun, J., \& Bae, K. S. (2000). Phylogenetic analysis of Bacillus subtilis and related taxa based on partial gyrA gene sequences. Antonie Leeuwenhoek, 78, 123-127.

Costacurta, A., Keijers, V., \& Vanderleyden, J. (1994). Molecular cloning and sequence analysis of an Azospirillum brasilense indole-3-pyruvate decarboxylase gene. Molecular and General Genetics, 243, 463-472.

Dashti, N., Zhang, F., Hynes, R., \& Smith, D. L. (1998). Plant growth promoting rhizobacteria accelerate nodulation and increase nitrogen fixation activity by field grown soybean [Glycine $\max (\mathrm{L}$.$) Merr.] under short season conditions.$ Plant Soil, 200, 205-213.

Dobbelaere, S., Croonenborghs, A., Thys, A., Vande Broek, A., \& Vanderleyden, J. (1999). Phytostimulatory effect of Azospirillum brasilense wild type and mutant strains altered in IAA production on wheat. Plant Soil, 212, 155-164.

Franzluebbers, K., Hossner, L. R., \& Juo, A. S. R. (1998). Integrated nutrient management for sustained crop production in sub-Saharan agriculture. Trop Soils/TAMU Technical Bulletin No. 98-03, 50 pp. 
Glick, B. R., Karaturovíc, D. M., \& Newell, P. C. (1995). A novel procedure for rapid isolation of plant growthpromoting pseudomonads. Canadian Journal of Microbiology, 41, 533-536.

Goel, A. K., Sindhu, S. S., \& Dadarwal, K. R. (2002). Stimulation of nodulation and plant growth of chickpea (Cicer arietnum L.) by Pseudomonas spp. antagonistic to fungal pathogens. Biology and Fertility of Soils, 36, 391-396.

Graham, P. H. (1981). Some problems of nodulation and symbiotic nitrogen fixation in Phaseolus vulgaris L.: A review. Field Crops Research, 4, 93-112.

Graham, P. H., \& Rosas, J. C. (1979). Phosphorus fertilization and symbiotic nitrogen fixation in common bean. Agronomy Journal, 71, 925-926.

Hamaoui, B., Abbadi, J. M., Burdman, S., Rashid, A., Sarig, S., \& Okon, Y. (2001). Effects on inoculation with Azospirillum brasilense on chickpeas (Cicer arietum) and faba beans (Vicia faba) under different growth conditions. Agronomie, 21, 553-560.

Hontzeas, N., Saleh, S. S., \& Glick, B. R. (2004). Changes in gene expression in canola roots induced by ACC-deaminase-containing plant-growth-promoting bacteria. Molecular Plant Microbe Interactions, 17, 865-871.

Kouas, S., Labidi, N., Debez, A., \& Abdelly, C. (2005). Effect of $\mathrm{P}$ on nodule formation and $\mathrm{N}$ fixation in bean. Agronomy for Sustainable Development, 25, 389-393.

Li, J., Ovakim, D. H., Charles, T. C., \& Glick, B. R. (2000). An ACC deaminase minus mutant of Enterobacter cloacae UW4 no longer promotes root elongation. Current Microbiology, 41, 101-105.

Lopez-Bucio, J., Hernandez-Abreu, E., Sanchez-Calderon, L., Nieto-Jacobo, M. F., Simpson, J., \& Herrera-Estrella, L. (2002). Phosphate availability alters architecture and causes changes in hormone sensitivity in the Arabidopsis root system. Plant Physiology, 129, 244-256.

Lugtenberg, B. J. J., Chin-A-Woeng, T. F. C., \& Bloemberg, G. V. (2002). Microbe-plant interactions: Principles and mechanisms. Antonie Leeuwenhoek, 81, 373-383.

Ma, W., Charles, T. C., \& Glick, B. R. (2004). Expression of an exogenous 1-aminocyclopropane-1-carboxylate deaminase gene in Sinorhizobium meliloti increases its ability to nodulate alfalfa. Environmental Microbiology, 70, 58915897.

Michiels, J., Moris, M., Dombrecht, B., Verreth, C., \& Vanderleyden, J. (1998). Differential regulation of Rhizobium etli rpoN2 gene expression during symbiosis and free-living growth. Journal of Bacteriology, 180, 36203628 .

Oldroyd, G. E., Engstrom, E. M., \& Long, S. R. (2001). Ethylene inhibits the Nod factor signal transduction pathway of Medicago truncatula. Plant Cell, 13, 1835-1849.

Ona, O., Van Impe, J., Prinsen, E., \& Vanderleyden, J. (2005). Growth and indole-3-acetic acid biosynthesis of Azospirillum brasilense $\mathrm{Sp} 245$ is environmentally controlled. FEMS Microbiology Letters, 246, 125-132.

Penmetsa, R. V., \& Cook, D. R. (1997). A legume ethyleneinsensitive mutant hyperinfected by its rhizobial symbiont. Science, 257, 527-530.

Pepper, J. L. (2000). Beneficial and pathogenic microbes in agriculture. In R. M. Maier et al. (Eds.), Environmental microbiology. San Diego: Academic Press.
Pereira, P. A., \& Bliss, F. A. (1987). Nitrogen fixation and plant growth of common bean (Phaseolus vulgaris L.) at different levels of phosphorus availability. Plant Soil, 104, 79-84.

Persello-Cartieaux, F., Nussaume, L., \& Robaglia, C. (2003). Tales from the underground: Molecular plant-rhizobacteria interactions. Plant, Cell and Environment, 26, 189199.

Plazinski, J., \& Rolfe B. G. (1985a). Azospirillum-Rhizobium interaction leading to a plant growth stimulation without nodule formation. Canadian Journal of Microbiology, 31, 1026-1030.

Plazinski, J., \& Rolfe, B. G. (1985b). Interaction of Azospirillum and Rhizobium strains leading to inhibition of nodulation. Applied and Environmental Microbiology, 49, 990-993.

Plazinski, J., \& Rolfe, B. G. (1985c). Influence of Azospirillum strains on the nodulation of clovers by Rhizobium strains. Applied and Environmental Microbiology, 49, 984-989.

Rainey, P. B., \& Bailey, M. J. (1996). Physical map of the Pseudomonas fluorescens SBW25 chromosome. Molecular Microbiology, 19, 521-533.

Raverker, K. P., \& Konde, B. K. (1988). Effect of Rhizobium and Azospirillum lipoferum inoculation on nodulation, yield and nitrogen uptake of peanut cultivars. Plant Soil, 106, 249-252.

Sambrook, J., Fritsch, E. F., \& Maniatis, T. (1989). Molecular cloning: A laboratory manual (2nd ed.). Cold Spring Harbor, N.Y.: Cold Spring Harbor Laboratory Press.

SAS Institute (1996). SAS user's guide: Statistics (6th ed.). Cary, NC: SAS Institute.

Schulze, J., Temple, G., Temple, S. J., Beschow, H., \& Vance, C. P. (2006). Nitrogen fixation by white lupin under phosphorus deficiency. Annals of Botany, 98, 731-740.

Sindhu, S. S., Gupta, S. K., \& Dadarwal, K. R. (1999). Antagonistic effect of Pseudomonas spp. on pathogenic fungi and enhancement of plant growth in green gram (Vigna radiata). Biology and Fertility of Soils, 29, 62-68.

Smith, D. L., \& Hume, D. J. (1987). Comparison of assay methods for nitrogen fixation utilizing white bean and soybean. Canadian Journal of Plant Science, 67, 11-79.

Snoeck, C., Verreth, C., Hernandez-Lucas, I., MartínezRomero, E., \& Vanderleyden, J. (2003). Identification of a third sulfate activation system in Sinorhizobium sp. strain BR816: The CysDN sulfate activation complex. Applied and Environmental Microbiology, 69, 2006-2014.

Srinivasan, M., Petersen, D. J., \& Holl, F. B. (1997). Influence of indoleacetic-acid-producing Bacillus isolates on the nodulation of Phaseolus vulgaris by Rhizobium etli under gnobiotic conditions. Canadian Journal of Microbiology, 42, 1006-1014.

Tchebotar, V. K., Kang, U. G., Asis, C. A., \& Akao, J. S. (1998). The use of GUS-reporter gene to study the effect of Azospirillum-Rhizobium coinoculation on nodulation of white clover. Biology and Fertility of Soils, 27, 349352.

Thilak, K. V. B. R., Ranganayaki, N., \& Manoharachari, C. (2006). Synergistic effects of plant-growth promoting rhizobacteria and Rhizobium on nodulation and nitrogen fixation by pigeonpea (Cajanus cajan). European Journal of Soil Science, 57, 67-71. 
Thung, M. (1991). Bean agronomy in monoculture. In A. V. Schoonhoven \& O. Voysest (Eds.), Common beans. Research for crop improvement (pp. 737-834). Wallingford, UK: CAB International.

Vadez, V., Lasso, J. H., Beck, D. P., \& Drevon, J. J. (1999). Variability of $\mathrm{N}_{2}$-fixation in common bean (Phaseolus vulgaris L.) under $\mathrm{P}$ deficiency is related to $\mathrm{P}$ use efficiency. Euphytica, 106, 231-242.

Vance, C. P. (1997). Enhanced agricultural sustainability through biological nitrogen fixation. In A. Legocki et al. (Eds.), Biological fixation of nitrogen for ecology and sustainable agriculture. Heidelberg, Germany: NATO ASI Series, Springer-Verslag.

Vance, C. P., Graham, P. H., \& Allan, D. L. (2000). Biological nitrogen fixation: Phosphorus-a critical need. In F. A. Pedrosa et al. (Eds.), Nitrogen fixation: From molecules to crop productivity (pp. 509-514). Netherlands: Kluwer Academic Publishers.

Vande Broek, A., Lambrecht, M., Eggermont, K., \& Vanderleyden, J. (1999). Auxins upregulate expression of the indole-3-pyruvate decarboxylase gene in Azospirillum brasilense. Journal of Bacteriology, 181, 1338-1342.

Van Noorden, G. E., Ross, J. J., Reid, J. B., Rolfe, B. G., \& Mathesius, U. (2006). Defective long distance auxin transport regulation in the Medicago truncatula super numeric nodules mutant. Plant Physiology, 140, 14941506.

Vessey, K., \& Buss, T. J. (2002). Bacillus cereus UW85 inoculation effects on growth, nodulation, and $\mathrm{N}$ accumulation in grain legumes - Controlled-environment studies. Canadian Journal of Plant Science, 82, 282-290.

Vincent, J. M. (1970). A manual for the practical study of rootnodule bacteria. Oxford: Blackwell Scientific Publishers.

Vlassak, K. M., Luyten, E., Verreth, C., van Rhijn, P., Bisseling, T., \& Vanderleyden, J. (1998). The Rhizobium sp. BR816 nodO gene can function as a determinant for nodulation of Leucaena leucocephala, Phaseolus vulgaris and Trifolium repens by a diversity of Rhizobium spp. Molecular Plant Microbe Interactions, 5, 383-392.

Volpin, H., Burdman, S., Castro-Sowinski, S., Kapulnik, Y., \& Okon, Y. (1996). Inoculation with Azospirillum increased exudation of Rhizobial nod-gene inducers by alfalfa roots. Molecular Plant Microbe Interactions, 1996, 388-394.

Woodward, A. W., \& Bartel, B. (2005). Auxin: Regulation, action and interaction. Annals of Botany, 95, 707-735.

Xie, H., Pasternak, J. J., \& Glick, B. R. (1996). Isolation and characterization of mutants of the plant growth-promoting rhizobacterium Pseudomonas putida CR12-2 that overproduce indoleacetic acid. Current Microbiology, 32, 67-71. 